Portland State University

PDXScholar

5-7-1993

\title{
Satisfaction with Social Support Among Recent Widows
}

Rachael Ann Silverman
Portland State University

Follow this and additional works at: https://pdxscholar.library.pdx.edu/open_access_etds

Part of the Urban Studies Commons Let us know how access to this document benefits you.

Recommended Citation

Silverman, Rachael Ann, "Satisfaction with Social Support Among Recent Widows" (1993). Dissertations and Theses. Paper 4672.

https://doi.org/10.15760/etd.6555

This Thesis is brought to you for free and open access. It has been accepted for inclusion in Dissertations and Theses by an authorized administrator of PDXScholar. Please contact us if we can make this document more accessible: pdxscholar@pdx.edu. 
AN ABSTRACT OF THE THESIS OF Rachael Ann Silverman for the Master of Urban Studies presented May 7, 1993.

Title: Satisfaction with Social Support Among Recent Widows APPROVED BY THE MEMBERS OF THE THESIS COMMITTEE:

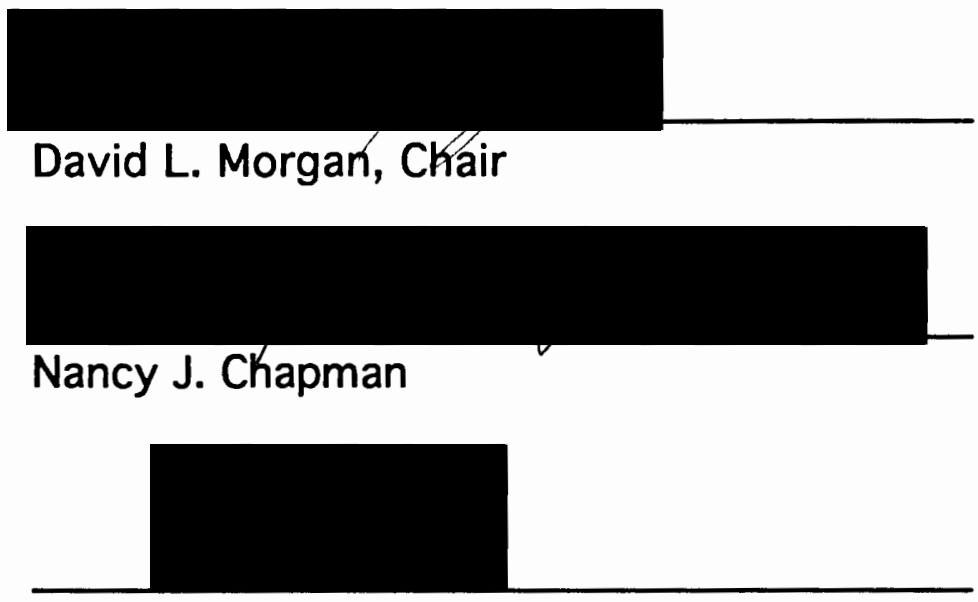

Hugo M. Maynard

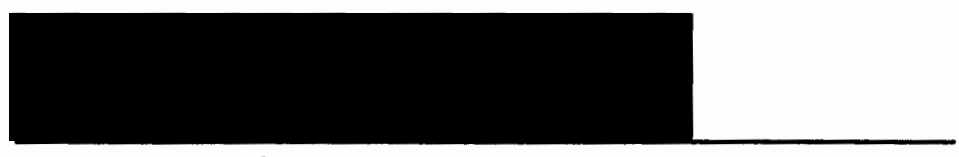

Maria M. Talbott

One of the important issues in research on social support has been the relationship between received support and perceptions of support. While most research has been unable to discover a strong link between these two constructs, three theories have emerged in the literature to explain how such a link might be discovered. One theory states that it is important to study support in the context of 
a stressful life event. Another suggests that when studying social support it is important to make distinctions between positive and negative interactions. A third approach focuses on specificity issues, predicting that it is important to specify the source, type and timing of support.

This study is concerned with widowhood and satisfaction with support. It addresses the questions present in the social support literature by focusing on five hypotheses. The first hypothesis predicts that while there will be more reported support than problems, the effects of the problems will be greater than the effects of the support. The second hypothesis anticipates a stronger link between received and perceived support than other studies have indicated. This is because this study is focusing on a widowhood as a stressful life event and is also differentiating between positive and negative interactions.

The third, fourth and fifth hypotheses focus on issues of specificity. The third hypothesis predicts that there will be a difference in satisfaction with family and non-family support. The fourth hypothesis looks at types of support and suggests that different forms of support and problems will affect satisfaction with family differently than satisfaction with non-family. The fifth hypothesis adds the temporal component, anticipating that satisfaction with different types of support and problems from family and non-family will vary over time.

Data for this study comes from the first year of a three year longitudinal research project conducted by the Institute on Aging at 
Portland State University. The sample consists of widows who live in the metropolitan area of Portland, Oregon. Potential respondents were contacted if their names appeared as the surviving spouse on a sample of death certificates. Widows were first contacted by mail, and if they indicated interest they were contacted later by phone. Women who were interested and eligible to participate were divided into three groups depending on length of time widowed. All the data used in this study is the result of one and a half hour long face-toface interviews with each of the respondents.

Received support was measured by asking respondents detailed questions about the kinds of help and problems they received from different network members. Perceived support was measured on a seven point scale which rated how satisfied widows were with their family and their non-family networks. Other important variables have to do with length of time widowed, size of networks, and frequency of contact with family and non-family network members.

Despite the overall prediction, that the amounts of support received will affect a person's satisfaction with support, the data only partially supported the five hypotheses. All the links between support, problems and satisfaction were in the non-family network. The only time that received support seemed to be significant was when examining non-family instrumental support among the most recent widows. Problematic interactions had increasingly stronger effects on satisfaction as the amount of time widowed increased. 


\title{
SATISFACTION WITH SOCIAL SUPPORT AMONG RECENT WIDOWS
}

\author{
by \\ RACHAEL ANN SILVERMAN
}

A thesis submitted in partial fulfillment of the requirements for the degree of

\author{
MASTER OF \\ URBAN STUDIES
}

Portland State University

1993 
TO THE OFFICE OF GRADUATE STUDIES:

The members of the Committee approve the dissertation of Rachael Ann Silverman presented May 7, 1993.
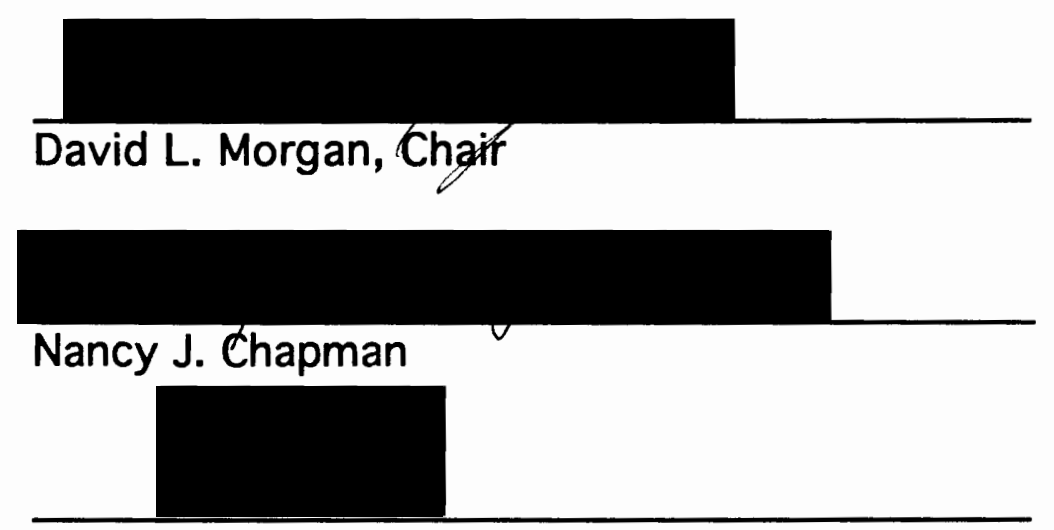

Hugo M. Maynard

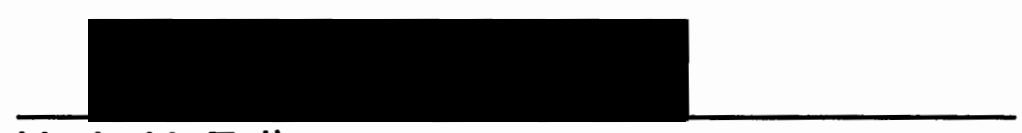

Maria M. Talbott

APPROVED:

Nancy Chapman, Chair, Department of Urban Studies and Planning

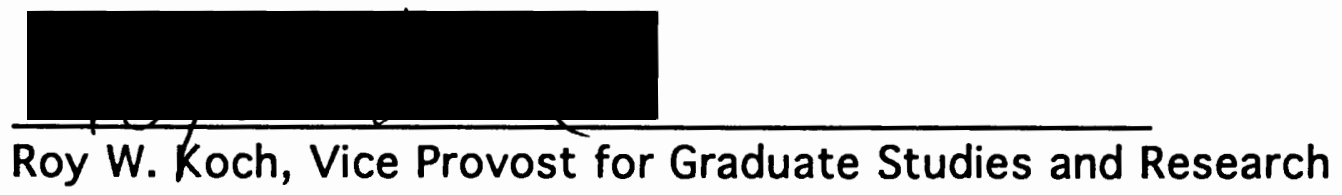




\section{TABLE OF CONTENTS}

PAGE

LIST OF TABLES .......................................................................................................

\section{CHAPTER}

1 SOCIAL SUPPORT AND WIDOWHOOD ............................................ 1

Introduction .................................................................................... 1

Support, Personal Relationships and Social

Networks

Considering both Social Support and Social

Strain .................................................................................

The First Hypothesis ......................................................... 9

Adding Perceived and Received Support ................... 10

The Second Hypothesis ........................................................... 17

Adding Specificity ........................................................... 17

Source Specificity ................................................................... 18

The Third Hypothesis............................................................221

Type Specificity ...................................................................... 21

The Fourth Hypothesis .......................................................24

Timing Specificity ...................................................................24

The Fifth Hypothesis ...........................................................29

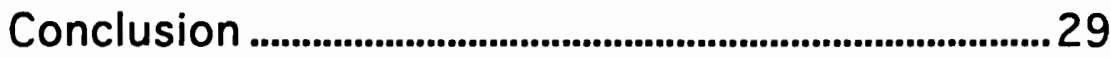

I I RESEARCH DESIGN AND METHODS ..............................................31 
Study Description ................................................................31

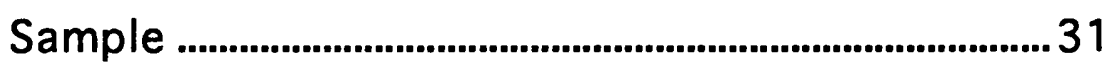

Measures ...........................................................................34

Received Support ...............................................................35

Perceived Support ............................................................36

Variables ...............................................................................36

III ANALYSIS _..........................................................................39

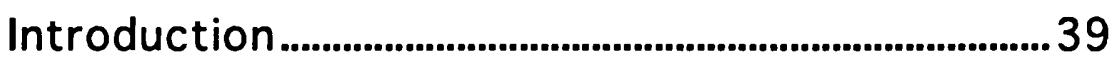

Results/Correlations and Descriptive

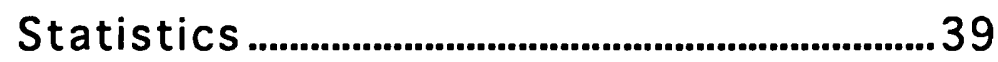

Results/Regression Analysis .......................................... 43

Summary of Findings ............................................................5 54

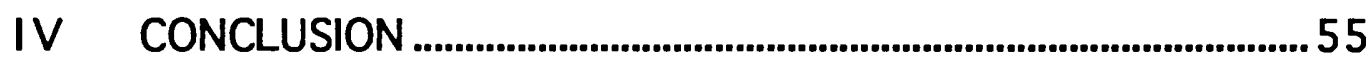

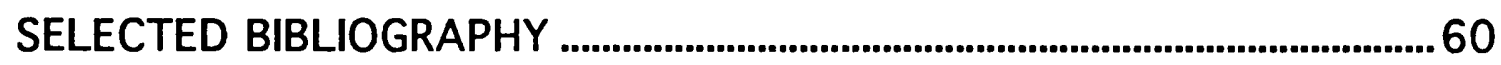




\section{LIST OF TABLES}

I Correlation Matrix Presenting Independent Variables and Satisfaction with Family

II Correlation Matrix Presenting Independent Variables and Satisfaction with Non-Family

III Means and Standard Deviations of Positive and

Negative Mentions for Family and Non-Family ..... 43

IV Effects of Network and Support Variables on

Satisfaction (Unstandardized Regression

Coefficients)

$V$ Effects of Network and Type of Problem on

Satisfaction with Non-Family (Unstandardized

Regression Coefficients)

VI Effects of Network and Support Variables on

Non-Family Satisfaction by Cohort

(Unstandardized Regression Coefficients)

VII Effects of Network and Type of Support on

Satisfaction with Non-Family by Cohort

(Unstandardized Regression Coefficients)/

Cohort One 
VIII Effects of Network and Type of Support on Problems with Non-Family by Cohort (Unstandardized Regression Coefficients)/Cohort One

IX Effects of Network and Type of Support on Problems with Non-Family by Cohort (Unstandardized Regression Coefficients)/Cohort Two

$X \quad$ Effects of Network and Type of Support on Problems with Non-Family by Cohort (Unstandardized Regression Coefficients)/Cohort Three. 


\section{CHAPTER I}

\section{SOCIAL SUPPORT AND WIDOWHOOD}

\section{INTRODUCTION}

Social support is a topic that invites different interpretations and applications. Underlying these approaches are some basic concepts about what social support is and the kinds of effects that it has on people's lives. Often social support is studied in conjunction with stress; stressful life events provide a lens with which to view and understand social support. Widowhood is one stressful life event that affects many elderly women. This paper uses the experience of widowhood as a context to explore certain aspects of social support: positive and negative interactions, the relationship between received and perceived support, and the source, type and timing of support. Chapter One will present a review of the literature and five hypotheses which address some of the questions that persist despite extensive research in this field. Chapter Two covers the methods and data that will be used in the analysis. Chapter Three presents the data analysis and findings while Chapter Four discusses the conclusions and refers to the original hypotheses.

It is important to note that widowhood is a particularly appropriate lens with which to view social support. Certainly different life events will differ in their support requirements: one 
kind of stressor may call for a quick emotional response from family while another event may need long term instrumental aid from friends. According to David Morgan and Stephan March (1992), life events enable the researcher to move beyond the structure of support systems to the actions that take place in support systems. In this study, widowhood is treated as a powerful and multifaceted life event that has many consequences for the surviving spouse. Research indicates that widowhood calls for changes in selfidentity and support reorganization. In a study on social support and life events conducted by Fran Norris and Stanley Murrell (1990), older adults who had lost a spouse were compared to older adults who had lost a parent or child. Those adults who had been widowed showed the longest lasting depression resulting from their loss. Kenneth Ferraro (1984) addresses the kinds of changes that widows and widowers may experience and writes that while there is some role loss, there is also a "shifting or realignment of relationships." Studies on widowhood also examine outcomes like health and wellbeing. (Bengston, Rosenthal, and Burton, 1990).

There is a great deal of literature on social support and this review will address the substantive issues in the social support field. One important topic has to do with what support actually is, that is, how social support should be defined. Many authors have noted a fragmented treatment of the concept of social support and have attempted to clarify its meaning and conceptual utilization (House, Umberson and Landis, 1988; Ferraro, 1989; Dunkel-Schetter and Bennett, 1990). Research is also concerned with the positive 
and the negative content of interactions (Morgan, 1989; Rook and Pietromonoco, 1987). While some literature focuses on the essence of social support (or social strain) and how it exists within personal relationships, other research adds the dimension of perception. These writers ask, is there a difference between perceived and received support? (Dunkel-Schetter and Bennett 1990; Sarason, Sarason, and Pierce, 1990; Schwarzer and Leppin, 1991). It is important to gather together these diverse approaches to support because as Toni Antonucci (1990) writes, questions concerning this construct have interfered with the development of the social support field.

Making distinctions between different kinds of support is a large part of the literature, but another topic has more to do with issues of specificity. Questions about specificity focus on the who, what, and when of support. Instead of assuming that support has an even and constant effect, some writers suggest that the source, type and timing of support make a difference in the kinds of outcomes that social support has. This may mean, for example, that there is a difference in effects between support from family and support from non-family, emotional support and cognitive support, and support during the early stages of grieving and support in the later stages of widowhood (Bankoff, 1983, 1984). 


\section{SUPPORT, PERSONAL RELATIONSHIPS AND SOCIAL NETWORKS}

Various writers have taken different approaches to the connection between social support, personal relationships and social networks. David Morgan (1990) and J. S. House, D. Umberson and K. R. Landis (1988) address these issues directly in two reviews. House et al., (1988), in their article "Structures and Processes of Social Support", first review the treatment of social support and health in the literature. They write that to better understand social relationships it is important to refine and add a greater sociological emphasis to the field. They make their major distinctions between the structure and processes of social support. House et al. believe that words like social relationships, social support and social networks have been used interchangeably and that these constructs can all fit under the umbrella of the structure of social relationships. They divide social structure into two categories. One category, social integration and isolation, refers to the existence and quantity of ties and the frequency of contact. The second category, social network structure, refers to the structure which characterizes the relationships by describing qualities like density and homogeneity.

They also describe social processes as having distinct qualities and state that social support should only be considered as one of three kinds of relational content that occur in a social relationship. They suggest that social support be considered as the positive health-promoting and stress-reducing aspects of 
relationships. Another important type of relational content consists of demands and conflict which have negative consequences. The third process they describe is that of social regulation or control which can be be either positive or negative, depending on the kinds of behavior and the way in which it is regulated. They further divide social support into three classes, instrumental aid, emotional caring and information. The authors suggest that if the three social processes are studied in relation to each other, a greater understanding might be achieved (House, Umberson and Landis 1988).

Other authors produce similar conceptions that suggest some differences but also present a whole picture. Morgan (1990) describes three constructs of social relationships that have been dominating the support literature. Social networks provide an overview of supportive relationships, each relationship in the network is seen in the context of every other relationship. Networks are described in terms of their characteristics: density, size, homogeneity and dispersion. Another perspective has to do with social support, that is, looking at actions in the context of individual personal relationships. Finally, some support research focuses on the nature of those relationships themselves.

Morgan (1990) suggests that these three perspectives have unique qualities but that they also overlap. The social network perspective is unique in that it emphasizes social relationships in a larger structure and does not view them in isolation. While this orientation allows relationships to be considered interactively and in terms of other relationships, it doesn't make sense to study 
structure without examining process. The social support perspective focuses instead on process and aids in the exploration of the positive and negative outcomes that people receive from social relationships. Like network analysis, when used alone it is incomplete. It derives its origins from stress and has resulted in a concentration of studies that explore the ameliorating effects of support on stress while overlooking the negative effects of relationships on stress. The personal relationships perspective allows for both positive and negative exchanges in relationships because it focuses on the processes and content occurring in specific relationships. This third perspective can also be limiting because relationships are studied one at a time instead of in a broader context.

Morgan suggests that these perspectives be combined. Social network studies don't have to limit themselves to structure if they incorporate social support theory, while personal relationship theory allows network theory to look at how the whole network might affect one relationship. Social support theory can be aided by network theory in studying how the network characteristics affect enacted support and the personal relationship perspective can allow social support theory to include both positive and negative consequences of relationships. Finally, personal relationship theory can be given a context by the network approach while considerations of social support allows a comparison of the content of different types of relationships. A combination of these three often distinct 
concepts allows a richer view of the way that social relationships can be supportive or unsupportive.

This discussion demonstrates not only diversity but also a sense of cohesion; these different approaches can work in concert to provide a deeper understanding. This attempt to synthesize concepts is similar to the approach of House et al. (1988) although Morgan (1990) emphasizes meaningful distinctions while House et al. are interested in emphasizing a sense of sameness. Morgan (1989; 1990) also stresses the importance of focusing on the negative as well as the positive aspects of social relationships. Morgan and House et al. believe that to understand support it is important to understand actions that are not supportive, either intentionally or unintentionally. Some writers have discussed negative aspects using the terminology "negative support." This is an unfortunate use of the word support, which essentially means positive and caring interactions. House, et al. solve this language problem by examining the relational content of people's relationships. The difference between positive and negative interactions is the focus of the next section.

CONSIDERING BOTH SOCIAL SUPPORT AND SOCIAL STRAIN

This section on social support and social strain suggests the need to differentiate between the positive and negative aspects of relationships. Karen Rook (1987; 1990a;1990b) has concentrated some effort on the meaning of negative interactions. In an earlier 
review article written with Paula Pietromonoco (1987), the authors suggest that current work on social support has focused too much on what it is about social relationships that reduce the adverse effects of life stress. They write that it appears that positive and negative interactions are different kinds of exchanges with different kinds of effects; they are not conceptual mirrors, located at opposite ends of a continuum. Positive and negative interactions are not correlated, and they are not produced by similar processes.

The authors create a framework for categorizing negative interactions which is quite similar to the approaches discussed above for categorizing different kinds of support. Ineffective help is help that either backfires, like bad or unwanted advice, or help that is offered grudgingly and perceived as such. Excessive help is a second type and can have effects on both the recipient and the caregiver; it might deteriorate relationships or create unhealthy dependencies. The third type of negative interaction is more intentional and includes unwarranted or unpleasant interactions such as criticism. The last type mentioned is negative regulation, which describes behavior like encouraging someone to eat or drink too much.

Rook and Pietromonoco (1987) also write that relationships change over time and that negative exchanges may become more common as relationships continue. They suggest that negative interactions are powerful experiences for three possible reasons. One reason is listed as frequency salience: because negative experiences are rarer than positive experiences, they are more 
salient. Another reason has to with the fact that negative interactions may actually reflect bad intentions or a lack of caring. Finally, the authors suggest that humans may have an innate tendency to focus more on risks than on pleasures.

In a later article focusing on older adults, Rook (1990a) reviews studies that indicate that negative interactions are detrimental to older people. She suggests that older adults might differ in how they are affected by negative interactions depending on the sheer number that they experience and their level of sensitivity. While some theorists have suggested that negative interactions are a result of the elderly's poor social skills, Rook cites studies which suggest that is not the case.

In another article published in 1990, Rook writes that the adverse effects of negative relationships may be stronger than helpful effects of positive relationships. She also coins the term "social strain" to be the counterpart to "social support." Social support and social strain are presented as separate constructs that should be operationalized differently. While common measures of support use happiness and satisfaction, appropriate measures of strain are depression, loneliness and anxiety.

\section{THE FIRST HYPOTHESIS}

The differentiation between social support and social strain leads to the first hypothesis. This study includes measures of both positive and negative interactions which allows the first hypothesis 
to predict that in general, there will be more reported support than reported problems, but the effects of the problems will be greater than the effects of the support.

\section{ADDING PERCEIVED AND RECEIVED SUPPORT}

Besides making distinctions between the positive and negative effects of interactions, researchers also ask how support that one believes to be available is related to or different from support that occurs. The literature defines these two kinds of support as perceived support and received support. Perceived support is the support that an individual perceives is available although it is not mobilized, and received support is support that has actually been enacted. This section discusses these two kinds of support with the intent of suggesting that they are different but related.

In "Social Support and Health: A Theoretical and Empirical Overview" by Ralf Schwarzer and Anja Leppin (1991), the authors present an interesting dimension and level of complexity to this discussion of support. They begin by writing that perceived support and received support need to be distinguished within the functional perspective and that they are usually uncorrelated. Perceived support is important in every day life and essentially acts as a sense of comfort (or discomfort) that support would (or would not) be available if needed. Received support, on the other hand, is important once a stressful life event occurs. After a stressful life 
event the perceived availability of support might still be important in determining an outcome.

Once support is mobilized, however, discrepancies can occur between perceived and received support: What the individual expects should happen and what actually occurs are different. The authors present a taxonomy to illustrate the ways that social support works. The first category includes social integration, social networks, and the relational content that refers to the positive and negative function of those relationships. The second distinction is cognitive or perceived support which derives meaning from the evaluation of available support done by the individual in need. The third division has to do with behavioral or received support, and the evaluation of support that is based on the actual receipt of support.

They also discuss the importance of the personality of the person receiving support and suggest that perceived support is affected by behavior characteristics including individual differences, stress appraisals and coping skills while received support and social integration are more related to social exchange. There are also transactional characteristics influenced by both the provider and the recipient.

The authors conduct a meta-analysis on health and social support and suggest that the relationship between the two might be underestimated; the negative association between support and illness could be mitigated by the effect of illness on mobilizing social support. They emphasize good causal models which will clarify both direct and indirect effects and suggest that research 
should address the timing of support and the types of support that are offered from different sources.

Barbara Sarason, Irwin Sarason and Gregory Pierce (1990a) also examine the differences between perceived and received support. They begin by looking at the multidisciplinary fields which give rise to disparate definitions of social support, stating that there is no coherent theory. They divide current theories of social support into three categories: 1) the network model, 2) the received model and 3) the perceived model. They believe that these distinctions represent a way to understand the social, pyschological and biological processes that link aspects of social support to an outcome, which in their case is health.

Sarason, Sarason and Pierce (1990a) define the network model as an approach which focuses on the individual's social integration and embeddedness in a group. They discuss network characteristics like size, density and frequency of contacts but believe that network analysis has not been a helpful way to approach support. This is partly a result of the lack of relational content in the analysis as well as because the effect of density is different depending on the kind of support needed. Network analysis is considered as an appropriate way to measure reciprocity in relationships. Received social support, the second category, has to do with support that has actually been enacted and received after a stressful life event occurs. Sarason et al. argue that received support represents a confounded picture of what kind of support is actually available, the 
individual's coping skills, and how others perceive the enormity of the stressful life event.

Network and received support measures indicate that what the recipient reports receiving is not always the same as what others report giving. Also, received support is only weakly linked with perceived support, and networks are only weakly linked with both received and perceived support. The authors believe that this indicates that it is perception in social support that is important. They write that many measures of social support can fit into a loosely defined perceived support category. One of these measures is availability of support, another of the measures is satisfaction with support. Some studies look at the current state of availability while others are interested in the perception of availability if the respondent happened to need it (Sarason, Sarason and Pierce, 1990a).

A detailed examination of the influences of personality on perceived support has been done by Sarason, Sarason and Pierce (1990b) in a chapter called "Social Support: The Sense of Acceptance and the Role of Relationships." They write that one of the most important developments in social support literature is that perceived support is understood to be the only aspect of social support to have an effect on health. Since much of what is considered supportive behaviors happens when people are under stress, and not all stressful situations are independent of personality, they suggest that some support is the result of individual characteristics. Using developmental psychology, the authors make a case for perceived social support as a sense of 
acceptance, emphasizing interpersonal skills, self-efficacy, low levels of anxiety and a positive view of self and the surrounding environment.

Other writers are also concerned about the differences between received and perceived support. Christine Dunkel-Schetter and Tracy L. Bennett (1990) begin their chapter in Social Support: An Interaction View with the common observation that there is a "lack of conceptual clarity" about social support. While they mention that there are distinctions between social integration, social networks and social support, they focus their discussion on the differences between perceived support (called available support) and received support. They begin their article with an overview of measurement approaches for the two kinds of support. They present more measurement options for received support than for perceived support, (although this may be because perceived support is operationalized as available support, without looking at satisfaction with support.)

They report different studies which have found differing levels of correlation between perceived and received support, ranging from a correlation of . 46 to a correlation of .10. They even report one negative value of $r=-.13$. Several reasons are suggested for this weak relationship between perceived support and support that is received. Some of these reasons have to do with judgements about how much support is expected. One theory, the victimization process, suggests that support systems are not always able to respond to stressful life events. This may be because members are 
also affected by the event, they may not know how to provide support and they may also blame the victim. Sometimes expectations for support are exceeded and the authors suggest that this is most likely with positive stressful life events. Also, it is possible that initial support will dissipate as personal resources by network members become depleted.

Other factors may also mediate the discrepancy. Individual differences of both the provider and the receiver may affect received support. Some providers may be more sensitive to others' needs and some people in need of support may be better at asking for help. Coping styles can also mediate between perceived and received support, for example, people who cope well mobilize more support than people who cope poorly. Finally, social network characteristics like size and density could be important; in a large network with low density different members may assume others are helping out.

Dunkel-Schetter and Bennett (1990) conclude their chapter by arguing that received support has buffering effects while perceived or available support has main effects. This means that received support will be most important when someone is actually undergoing a stressful life event. If there is no stressful life event, received support will be less important. Perceived support, however, will always have a positive effect on an individual whether or not that person is undergoing stress. They suggest that past research on received support may have been inconclusive because the context of received support has been ignored and measures of support, stress 
and well-being have not always been at the same level of specificity.

Dunkel-Schetter and Bennett (1990), Sarason et al. (1990a; 1990b) and Schwarzer and Leppin (1991) all conclude that the link between received support and perceived support is weaker than expected. Sarason, et al. (1990a; 1990b) and Schwarzer and Leppin (1991) present similar arguments. Schwarzer and Leppin (1991) describe the dichotomy of support within a functional context and Sarason et al. (1990a) present a trichotomy that differentiates from the structure of support (the network mode) and the actual receipt of support (the received/perceived dichotomy.) Sarason, et al. (1990a;1990b), focus ultimately on the characteristics of the individual who needs aid as the reason for the weak relationship. Schwarzer and Leppin (1991) concur that this is likely to be a reason, but they point to other issues as well: memory, expectations, characteristics of both the recipients and providers of support, network characteristics and the transactional process between both the provider and the recipient of support.

Dunkel-Schetter and Bennett (1990) add to the discussion by providing another reason for the low correlation between received and perceived support; they believe that received support needs to be approached with a firmer grasp on issues of specificity and context. That is, it is important to specify the source, type and timing of support as well as the life event which dictates the need for support. Although Schwarzer and Leppin (1991) allude to this importance, Dunkel-Schetter and Bennett (1990) make the strongest 
case. Before the discussion turns to issues of specificity, the second hypothesis can be presented.

\section{THE SECOND HYPOTHESIS}

While other studies have found weak relationships between perceived and received support, this hypothesis predicts a stronger predictive relationship. This makes sense for two reasons. The first is that this research takes into account both positive and negative interactions, and the second is that this research takes into account the stressful life event of widowhood. Focusing on support and strain as well as context will allow for a more complete understanding of received and perceived support.

\section{ADDING SPECIFICITY}

David Jacobson (1986) discusses specificity issues He begins his discussion examining theories of stress and theories of support. The "needs" model of stress suggests that unmet needs create stress, the "transactions" model of stress describes a situation in which perceived demands exceed perceived resources, and in the "transitions" model of stress, stress occurs as a result of role changes. He also matches up types of support to these types of stress. For example, if stress is defined as unmet needs, then support is providing those needs. Or if stress is defined in the 
transaction model, support might be conceptualized as a way to redress imbalances.

Jacobson (1986) moves beyond these discussions of the stressful event and support to discuss other issues of specificity. Although he focuses on the timing of support, he states the importance of source and type specificity as well. Discussion will now turn to the specificity of widowhood as a stressful life event, and issues of the source, type and timing of support in that context.

\section{SOURCE SPECIFICITY}

This section explores the sources of support with the idea that different sources of support will have different impacts. In an early article, George Arling (1976) enforces this concept by examining relationships between elderly widows, their friends, neighbors and family. He writes that widowhood, an event which constitutes great change in an older person's life, forces the widow to realign her relationship with other family members. Jacobson (1986) would call that a transitional model of stress. Arling (1976) writes that contact with family members remains strong for older women and widows often have close relationships with children, especially daughters. Still, the impact of family relationships on morale is ambiguous. He suggests two reasons: often elderly people and their children have different interests and do not make good companions, and older widows are unable to reciprocate for the support and service provided by their children. On the other hand, morale is 
found to be positively associated with contact with friends as friends do make good companions and there is a degree of reciprocity.

Arling (1976) also reports that relationships with family, friends and neighbors can not be substituted for each other. He hypothesizes that reciprocity is an important part of the widow's social relationships and finds that family ties are unrelated to morale while neighbor-friendship ties are significantly related to morale. However, he also states that he does not mean to say that family ties are incidental and detrimental to elderly widow's wellbeing. His argument ends with the suggestion that avoiding the reversal of roles with aged parents and their children will mean that parents will have to maintain some autonomy.

Other writers take this concept of specificity and ask similar questions about bereavement and widowhood. In a discussion about social networks and widowhood, Morgan (1989) compares the negative aspects of widows' relationships with their families to their relationships with their friends. Using focus group discussion, he asks women about their social networks since the death of their husbands. After asking participants what kinds of things made widowhood easier and what kinds of things made widowhood harder, Morgan (1989) finds that many widows are unhappy with their family. He differentiates between intentional and unintentional negative effects and writes that while family is mentioned more often than friends in a negative way, much of this difference is made up of unintentional negative behaviors. Widows may be 
unhappy with their parents because of obligations and they may be upset when their children are unable to accept their feelings and criticize their coping abilities. Widows are also upset with nonfamily who don't accept their feelings and push them to recover. Ultimately, Morgan (1989) says that widows are more likely to exhibit commitment to relationships with family members, even if they do not behave supportively, and are more likely to substitute positive non-family relationships for problematic ones.

Maria Talbott (1990) agrees with Arling (1976) and Morgan (1989) that there are negative aspects of the relationship between older widows and their children but doesn't support Arling's argument that this is because elderly widows are unable to reciprocate with their adult children. She suggests, instead, that this dissatisfaction may be a result of stress associated with the giving that they do for their children; they may feel unappreciated or they may be providing support that is beyond their means. She also writes that women may worry about feeling like a burden to their children, they may be emotionally dependent and they may feel neglected.

The literature on source specificity extends beyond widowhood. In the recent article "Specifying the Buffering Hypothesis: Support, Strain and Depression", Pamela Braboy Jackson (1992) discusses the concept of the buffering effect of stress along with specificity issues. She suggests that spouses will be less effective than friends in buffering the support of familial role strains but that spouses will be more helpful in buffering 
nonfamilial role strains. She also hypothesizes that spouses will buffer ambient strains more effectively. Her hypotheses are only partially supported. Spouses are found to be able to alleviate all types of life strains while friends are better at alleviating ambient strains and role strains relating to marriage. Although her writing is not centered on widowhood as a stressful life event, this research clearly indicates the importance of source of support specificity. This particular issue leads to the third hypothesis.

\section{THE THIRD HYPOTHESIS}

Based on these studies there should be a difference in satisfaction with family and non-family networks. It is predicted that support and problems will have different effects on levels of satisfaction, depending on whether the source is family or nonfamily.

\section{TYPE SPECIFICITY}

While the third hypothesis focuses on distinctions between family and non-family, this section will focus on another important specificity distinction: type of support. As in the previous section on source specificity, this discussion leads to a hypothesis regarding the importance of specifying what kind of support is received. In an article about social support networks, Kenneth Walker, Arlene MacBride and Mary Vachon (1977) write about 
different types of support and the influence of network characteristics on that support. Network characteristics examined have to do with size, strength of ties, density, homogeneity of members and dispersion of members. The authors hypothesize that the maintenance of a social identity is best done by a small, strong, dense, homogeneous and close network. Emotional support is best done by a dense and homogeneous network where there is some similarity of experience and little dispersion. Material aid and services is most likely to be provided by a dense and strong network but access to new knowledge and new social contacts is most likely to come from a network that is less dense and has some weak ties.

This suggests that a small, dense network with strong ties is best for crises that do not involve role changes or loss of resources. However, in the case of a major transition, a small dense network may confine and limit an individual instead of allowing for a transition. In the case of bereavement and widowhood, during the period of intense grief after the death of a spouse when there is a positively perceived and clear widow role, a dense, strong and homogeneous network with strong ties is most effective at providing support. The authors note that in Western society, however, widows do not always have a clear and supported role. They also write that during the later stages of grief as the widow is attempting to redefine her life, a dense network is unlikely to be helpful. Instead the widow may need a network with weaker ties that is able to help the widow transition to a changing social identity. The importance of network density is reinforced by Barton 
Hirsch (1980) who studied younger widows returning to school. He suggests that networks with lower densities facilitate a more successful adaptation to new roles.

Shirley O'Bryant and Leslie Morgan (1990) also explore type specificity by examining the kinds of support that adult children provide to their widowed mother. They find that despite the assumption that widows need task support, most recently widowed women in their study scored moderate to high on self-sufficiency; self-sufficiency was affected significantly by age, health, autonomy and prewidowhood task experience. Widows also varied significantly on their need for different kinds of support, and many received some kind of assistance. Household repairs is the category in which almost $70 \%$ of the respondents received help while only $1 \%$ received help with bathing. Few unmet needs are reported and assistance is sex typed, that is daughters provided help for traditionally female tasks and sons provided help for traditionally male tasks.

Frequency of help is dependent on the type of support, not on the source of support, which is categorized as either children, other kin or non-family. The authors describe two models of informal support systems but believe neither model sufficiently explains their results. One model proposes that providers are chosen on the basis of kinship and closeness, the other model suggests that providers are chosen on the basis of competence. Findings indicate that while children appear to be named the most often as providers, that may be the most logical choice. Two network traits are 
positively associated with children doing more network tasks: more children and a greater perception that children are willing to help. Increased perceived willingness is negatively correlated with distance between the recipient and the provider. Also, while the variables autonomy and orientation towards tasks affect selfsufficiency, they do not affect the proportion of help a widow receives from her children (O'Bryant, Morgan 1990).

\section{THE FOURTH HYPOTHESIS}

The fourth hypothesis predicts that different forms of support and problems will affect satisfaction with family differently than satisfaction with non-family. The existing literature does not provide enough information to yield predictions about which types of support or problems (i.e. advice, instrumental or emotional) will matter more when they come from one source or another. Still, it makes sense to expect differences with satisfaction and types of support and problems from family and non-family networks.

\section{TIMING SPECIFICITY}

In this section the importance of the timing of support is examined. Like the two sections above, the result of this discussion is a hypothesis suggesting increased specificity. Elizabeth Bankoff (1983; 1984), in two articles about social support and widowhood, discusses not only source and type specificity, but also examines 
the impact of timing. She asks essentially four questions: 1) Does social support from a significant other make a difference to the psychological well-being of the widow? 2) Do types of support affect well-being? 3) Do sources of support affect well-being? Does timing of support make a difference? In "Social Support and Adaptation to Widowhood" Bankoff (1983) queries as to why widowhood is not associated with an increase in psychopathology and suggests that there are psychological mediators. In an attempt to understand these mediators the author examines the buffering effect of social networks. She writes that past research has not given adequate treatment to type specificity and timing of support; since bereavement moves through a distinct process, it makes sense that the who and what of support could change depending on the phase of bereavement of the widow.

Bankoff (1983) describes the bereavement process as starting in crisis, when the life of the survivor has been drastically changed and that person's world has become meaningless. Grieving takes precedence over all other changes, such as role loss and material needs. During the next phase, the transition phase, the bereaved attempts to reconnect with the world and resume a normal life. Finally, the bereaved resumes a normal life.

In the article from 1983, Bankoff collects data by mail from women who had been widowed for less than three years. She divides them into two groups, one to represent the crisis-loss-phase (women who have been widowed less than 18 months) and one for the transition phase. Type of support is measured with 6 categories: 
contact support, intimacy support, emotional support, guidance support, dependability support and sanction support. These support types lean in the direction of emotional support. She also asks questions about different networks, both family (parents, in-laws, children and other relatives) and non-family (widowed/single friends, married friends, and neighbors.) She finds that source specificity is more important than type specificity and that timing of support is clearly important; different networks effectively meet widows' needs depending on the different adjustment phases.

Results indicate that in the crisis-loss-phase of bereavement only parental, (most likely the widowed mother), and widowed friends' support is effective at increasing well being. In the transition phase more networks are able to be supportive and while widowed friends are the most effective, neighbors, parents and children are moderately associated with an increase in well-being. Bankoff (1983) interprets these results by stating that in the crisis-loss phase grieving individuals are withdrawing and most sources of support are not effective. Parental support is important because widows most need an undemanding and nurturing place to grieve. In the transition phase more sources of support are effective because widows are reaching out. Parental support decreases in importance because this phase requires less grieving and more life reconstruction; instrumental support may be important. She suggests that children's support may be ineffective in the first 18 months because the children are also grieving. It is interesting that she does not find much difference due to support 
type, although this may be because of the typology that she has created.

Bankoff's paper presented in 1984, "The Long Term Consequences of Social Support for Newly Widowed Women," focuses on what Bankoff calls the crisis stage, defined as the first 18 months. She asks about the long term impacts of early social support, and using a sub-sample of the sample mentioned above, divides the group into the crisis phase (the first nine months after the loss) and the post-crisis phase (the second nine months after the loss.) Using the same sources and types of support as above she asks if early support has a long term impact on the widows' wellbeing.

She finds that early support from other widows and children are important to the widows' sense of well being three years later. Widowed friends' positive support as well as the negative effects of children's support seems to occur in the first nine months. These results suggest that the early months of bereavement have long term consequences. Bankoff (1984) continues to offer reasons for the negative impact of children's support suggesting, among other reasons that the widow may need to appear strong in front of the children and that adult children may be uncomfortable seeing their mother in a crisis stage. Also, children may provide inappropriate advice and guidance while widowed friends are more effective. Elderly parents may not have long term effects because, like the widows' children, they are unable to provide helpful guidance. 
David Jacobson (1986) also discusses specificity issues and stresses that it is important to examine timing of support. He notes that both stressors and support occur over time and he uses different models of stress to elucidate the importance of understanding how support is timed. Two theories of stress, the transaction theory, which suggests stress is the result of demands exceeding resources, and the transition theory, which postulates that stress is the result of role changes, focus on the timing of support. Jacobson calls for the integration of theories of support with theories of stress. He writes that much of the understanding of social support has to do with process and timing; stressors transform the latent need into a manifest need for support. Examples of this in the literature are that stressful life events change the main effect of support into the buffering effect, potential (perceived) support into actual (received) support and potential members of a network into actual service providers. According to Jacobson (1986), integrating typological and the process aspects of support can explain more about the efficacy of support.

Support specificity of all types is also discussed in "The Role of Social Support in Bereavement" by Vachon and Stanley Stylianos (1988). Reviewing the literature, they cover much of what has been presented in this chapter. They write that the goodness of fit between network members' activities and the recipient's needs is "governed by the amount, timing, source, structure and function of support." Personality factors as well as perceived support are 
important and since there is no way to measure the exact helpfulness of a support system, assessment should be the result of the recipient's appraisal. Family is involved in the initial stage of grief, friends and new friends become more important as time goes on. The authors also discuss the difference between unhelpful and helpful support, stating that some unhelpful interactions occur at the preconscious level.

\section{THE FIFTH HYPOTHESIS}

This hypothesis suggests that different forms of support and problems will affect satisfaction with family differently than satisfaction with non-family, and these differences will vary over time. Again, the literature does not provide enough information to yield predictions about which forms of support and problems will matter more depending on network and cohort.

\section{CONCLUSION}

This review has presented an examination of the conceptualization and measurement aspects of social support. While there are diverse approaches to conceptualization and measurement, there are also opportunities for cohesion and agreement. This thesis attempts to weave the variety of approaches together and investigate five important hypotheses. The hypotheses take into account both positive and negative interactions, the linkage between 
perceived and received support, and source, type, and timing of support within the context of a powerful and stressful life event. The first hypothesis predicts that while there will be more reported support than problems, the effects of problems will be larger than the effects of support. The second hypothesis states that the relationship between perceived and received support will be stronger than previous research suggests. The third, fourth and fifth hypotheses focus on issues of specificity. These hypotheses predict that there will be a difference between family and non-family support, and that satisfaction with support will vary by source, type and amount of time from the spouse's death. The last three hypotheses are also exploring the link between received and perceived support with greater specificity. The next chapter will describe the methods used in this paper to explore the power of these hypotheses. 
CHAPTER II

RESEARCH DESIGN AND METHODS

STUDY DESCRIPTION

The data used in this research comes from the initial interview of a three year longitudinal study. The research, conducted by the Institute on Aging at Portland State University, is funded by the National Institute on Aging. The stated goal has to do with examining how changes over time in social networks affect widows' coping ability. Issues of perceived and received support are also a component of this study. The data are particularly rich and are easily able to answer the hypotheses proposed in the previous section. Eventually all respondents who have completed the study will have participated in a year of interviewing: three face-to-face interviews conducted at six month intervals and four telephone interviews, two between the first and the second face-to-face interview, and two between the second and the third face-to-face interview.

\section{SAMPLE}

The sample consists of widows who live in the metropolitan area of Portland, Oregon. Women were contacted with the 
cooperation of the Oregon State Health Division. Death certificates of men at least 60 years old provided the names of surviving spouses and potential research participants. Each woman was sent a letter explaining the purpose of the study.and women who thought they might be interested indicated so on a reply card that they returned in a previously stamped and addressed envelope. Those women received phone calls which explained the study in more detail and ascertained eligibility. The main criterion besides amount of time widowed was age: the sample was limited to women who at the time of their spouse's death were in the 60 to 80 year old range. The age criterion was to control for differences between younger widows and older widows.

Women who indicated they were not interested were not followed up. If the envelopes were returned undeliverable, attempts were made to contact these women using directories. Of the 2331 letters mailed, 215 were ultimately undeliverable and 2116 letters were delivered. Of those 2116 letters delivered, 1123 (53\%) did not reply and 993 (47\%) did reply. Of those who did reply, 484 (46\%) agreed to participate, $448(45 \%)$ indicated they did not want to participate and $61(6 \%)$ were unavailable because they had moved or died. Those who participated represented only $23 \%$ of the total number of delivered letters and $21 \%$ of the total contacts.

Women who replied that they did not want to participate had different reasons. Although the letter stated that the study was not a counseling or support group experience, $15.5 \%$ of all women replied that they did not want to participate because they were 
already coping adequately. $28 \%$ of those not participating were too busy, $19 \%$ were in poor health, $8 \%$ were too upset and $9.5 \%$ were either not interested or felt they wanted to maintain their privacy.

To get at differences related to the length of time widowed, the sample is divided into three groups. The first group is women who have been widowed for 3 to 6 months, the second group have been widowed for 15 to 18 months and the third group have been widowed for 27 to $\mathbf{3 0}$ months prior to the initial interview. These groups from now on will be addressed as the first-year cohort, the second-year cohort and the third-year cohort. Although the data for the first year of the study is cross sectional, the three groups do provide a longitudinal vision of the experience of widowhood. While it is reasonable to expect that there are not any differences due to the characteristics of the population which would affect the results, selection bias is possible. However, women's willingness to participate was not affected by cohort, although the third cohort was oversampled since that group was harder to reach.

Information used has been collected in a one hour and half long face-to-face interview. Most interviews took place at the respondent's house although a few were in public places such as restaurants. Interviews were conducted by 11 interviewers who participated in ongoing training about the survey instrument, as well as training about widowhood in general. At the end of the initial interview each participant received a list of community resources available to widows. 


\section{MEASURES}

The measures used for this study are related to social networks and social support. Respondents' answers to several questions will be used to understand received support, perceived support and the relationship between the two. Respondents were asked to list the members of their social networks, both family and non-family. The total network could include up to thirty names; the widow was initially asked to list no more than ten names of family members and ten names of non-family members, but she was able to add five more people to each category later in the interview if she felt she had left someone out.

The names are placed in a concentric diagram made up of three circles. One diagram is for family and the other for non-family. The innermost circle is for those network members who are closest to the respondent. The middle circle is for those who are important but not as important as the first group, and the outer circle is for those who are still important but not as important as the first two groups. These diagrams are shown to the respondents and referred to throughout the interview.

More data were collected about each network member including age, type of relationship and frequency of contact. Two baseline variables that this study included are Frequency Of Contact and Size Of Networks. Contact frequency is important because respondents may get more satisfaction from relationships in which there is a higher rate of contact, either in person or by phone. Network size 
may also be important, although a large network might mean more support, or it might mean that members think that other members are providing support so that they don't have to.

\section{RECEIVED SUPPORT}

After the two network diagrams were initially filled with a combined total of twenty names, the respondent was asked about received support. Received support is support which has actually been enacted. To get at received support, the respondent listed the names of each member who has had a positive or negative effect on her life regarding specific types of actions. The first question reads:

One way for people to have a positive effect on your life is to give you helpful advice and information. Some of the things that this might include are helping you when you're unsure about what decisions to make and helping you find information that you are interested in.

This question has to do with cognitive support and there are similar questions for emotional support ("showing love and affection or accepting you or understanding you without judging you") and instrumental support ("helping you with bigger things such as taking care of you when you are sick. . . or helping you with smaller things such as housework. ..") Similar questions have to do with negative effects. For example, regarding cognitive support: 
One way that people can have a negative effect on your life is when there are disagreements about advice and information. Some of the things this might include are questioning your decisions or giving unwanted or bad advice.

\section{PERCEIVED SUPPORT}

Perceived support, the way that respondents feel about support that is available, is measured differently. Research participants were asked to measure their satisfaction with network members on a 1-7 Likert scale and follow up with an open ended probe. Answers ranged from extremely satisfied to extremely dissatisfied. One question was asked about family network members and another was asked about non-family network members. An example regarding family members is:

Overall, considering both the help you get and the problems that you have with your family in these three areas, how satisfied or dissatisfied would you say that you are?

Could you tell me a little about your reason for saying that?

\section{VARIABLES}

The data analysis included several variables relating both to the social network and social support. Variable 1 indicates the size of the family network. Variable 2 has to do with the number of people in the non-family network. Variables 3 and 4 have to do with 
frequency of contact with family and non-family members, respectively. Variables $5,6, .7$ and 8 have to do with received support from family members. Variable 5 has to do with emotional support, Variable 6 indicates instrumental support, and Variable 7 is related to advice and information, or cognitive, support. Emotional support is support that revolves around emotions and feelings, and instrumental support refers to help with things that need done. The third category, advice and information, has to do with help in tasks like making decisions or getting new information. Variable 8 measures the total number of mentions by adding up the totals for variables 5,6 , and 7 .

Variables $9,10,11$, and 12 are the same as 5-8 except that they refer to nonfamilial network members. Variable 9 represents emotional support, Variable 10 has to do with instrumental support, and Variable 11 is cognitive support from non-family. Variable 12 measures the total number of support mentions for non-family.

Variables 13-20 have to do with the possible negative effects of network members. Variable 13 has to do with emotional problems from family, Variable 14 indicates instrumental problems from family, and Variable 15 measures cognitive problems from family. Variable 16 adds up the negative mentions. Variable 17 is related to emotional problems from non-family, Variable 18 has to do with instrumental problems from non-family, and Variable 19 indicates cognitive problems from non-family. Variable 20 sums these nonfamily mentions. Finally, perceived support for family is measured 
with Variable 21 and Variable 22 does the same for satisfaction with non-family.

There are also three dummy variables which identify the cohort of the participant. A value of 1 for Variable 23 indicates the respondent is in cohort one, a value of 1 for Variable 24 states the respondent is in cohort two, and a value of 1 for Variable 25 means that the respondent is in cohort three. 
CHAPTER III

ANALYSIS

INTRODUCTION

This analysis uses multiple linear regression to explore the relationship between the independent variables related to received support and the dependent variables regarding perceived support. Received support is measured by asking respondents what kind of support they received and from who, while perceived support rates their satisfaction. Variables measuring cohort are also used to further specify support.

\section{RESULTS/CORRELATIONS AND DESCRIPTIVE STATISTICS}

Before beginning a discussion of the regression findings, it is useful to get an idea of which variables are correlated with each other. Table I, a correlation matrix using the variable Satisfaction

\section{TABLE I}

CORRELATION MATRIX PRESENTING INDEPENDENT VARIABLES AND SATISFACTION WITH FAMILY

\begin{tabular}{|l|l|l|l|l|l|l|l|l|l|l|l|l|}
\hline & $\begin{array}{c}\text { Sat } \\
w / f\end{array}$ & $\begin{array}{c}\text { Sat } \\
w / n f\end{array}$ & $\begin{array}{c}\text { Fam } \\
\text { size }\end{array}$ & $\begin{array}{c}\text { Num } \\
\text { cont }\end{array}$ & $\begin{array}{c}\text { Ad/ } \\
\text { sup }\end{array}$ & $\begin{array}{c}\text { Em/ } \\
\text { sup }\end{array}$ & $\begin{array}{c}\text { Instr/ } \\
\text { sup }\end{array}$ & $\begin{array}{c}\text { Tot } \\
\text { pos }\end{array}$ & $\begin{array}{c}\text { Ad/ } \\
\text { prob }\end{array}$ & $\begin{array}{c}\text { Em/ } \\
\text { prob }\end{array}$ & $\begin{array}{c}\text { Instr/ } \\
\text { prob }\end{array}$ & $\begin{array}{c}\text { Tot } \\
\text { neg }\end{array}$ \\
\hline $\begin{array}{l}\text { Sat } \\
w / f\end{array}$ & 1 & & & & & & & & & & & \\
\hline
\end{tabular}


TABLE 1

CORRELATION MATRIX PRESENTING INDEPENDENT VARIABLES AND SATISFACTION WITH FAMILY (continued)

\begin{tabular}{|c|c|c|c|c|c|c|c|c|c|c|c|c|}
\hline & $\begin{array}{l}\text { Sat } \\
w / f\end{array}$ & $\begin{array}{l}\text { Sat } \\
w / n f\end{array}$ & $\begin{array}{l}\text { Fam } \\
\text { size }\end{array}$ & $\begin{array}{l}\text { Num } \\
\text { cont }\end{array}$ & $\begin{array}{l}\overline{\mathrm{Ad} /} \\
\text { sup }\end{array}$ & \begin{tabular}{|l|}
$\mathrm{Em} /$ \\
sup
\end{tabular} & $\begin{array}{c}\text { Instr } \\
\text { sup }\end{array}$ & $\begin{array}{l}\text { Tot } \\
\text { pos }\end{array}$ & $\begin{array}{l}\mathrm{AdV} \\
\text { prob }\end{array}$ & $\begin{array}{l}\text { Em/ } \\
\text { prob }\end{array}$ & $\begin{array}{c}\text { Instr| } \\
\text { prob }\end{array}$ & $\begin{array}{l}\text { Tot } \\
\text { neg }\end{array}$ \\
\hline $\begin{array}{l}\text { Sat } \\
w / n f\end{array}$ & $\begin{array}{l}.27 \\
\star \star\end{array}$ & 1 & & & & & & & & & & \\
\hline \begin{tabular}{|l|} 
Fam \\
size
\end{tabular} & .05 & -.04 & 1 & & & & & & & & & \\
\hline $\begin{array}{l}\text { Num } \\
\text { cont }\end{array}$ & .09 & .05 & $\begin{array}{l}.49 \\
\star \star\end{array}$ & 1 & & & & & & & & \\
\hline $\begin{array}{l}\text { AdV } \\
\text { sup }\end{array}$ & .07 & .00 & $\begin{array}{l}.47 \\
\star \star\end{array}$ & $\begin{array}{l}.30 \\
\star \star\end{array}$ & 1 & & & & & & & \\
\hline $\begin{array}{l}\text { Em/ } \\
\text { sup }\end{array}$ & .02 & .02 & $\begin{array}{l}.65 \\
\star \star\end{array}$ & $\begin{array}{l}.39 \\
\star \star\end{array}$ & .04 & 1 & & & & & & \\
\hline $\begin{array}{l}\text { Inst// } \\
\text { sup }\end{array}$ & .02 & .01 & $\begin{array}{l}.50 \\
\star \star\end{array}$ & $\begin{array}{l}.41 \\
\star \star\end{array}$ & .05 & $\begin{array}{l}.50 \\
\star \star\end{array}$ & 1 & & & & & \\
\hline $\begin{array}{l}\text { Tot } \\
\text { pos }\end{array}$ & .04 & .01 & $\begin{array}{l}.70 \\
\star \star\end{array}$ & $\begin{array}{l}.46 \\
\star \star\end{array}$ & $\begin{array}{l}.73 \\
\star \star\end{array}$ & $\begin{array}{l}.88 \\
\star \star\end{array}$ & $\begin{array}{l}.77 \\
\star \star\end{array}$ & 1 & & & & \\
\hline $\begin{array}{l}\mathrm{Ad} / \\
\text { prob }\end{array}$ & .04 & .09 & $\begin{array}{l}.20 \\
\star *\end{array}$ & .07 & .08 & .01 & $\begin{array}{c}.12 \\
\star\end{array}$ & .07 & 1 & & & \\
\hline \begin{tabular}{|l|}
$\mathrm{Em} /$ \\
prob
\end{tabular} & .01 & .01 & $\begin{array}{c}.12 \\
\star\end{array}$ & .00 & -.02 & -.04 & -.01 & -.03 & $\begin{array}{l}.37 \\
\star * \star\end{array}$ & $\overline{1}$ & & \\
\hline $\begin{array}{l}\text { Inst/ } \\
\text { prob }\end{array}$ & -.02 & .02 & $\begin{array}{c}.13 \\
\star\end{array}$ & .10 & .04 & -.03 & .04 & .01 & $\begin{array}{l}.35 \\
\star \star\end{array}$ & $\begin{array}{l}.35 \\
\star \star *\end{array}$ & $\overline{1}$ & \\
\hline \begin{tabular}{|l|} 
Tot \\
neg
\end{tabular} & .01 & .05 & $\begin{array}{l}.19 \\
\star \star \star \\
\end{array}$ & .07 & .04 & -.03 & .07 & .02 & $\begin{array}{l}.75 \\
\star \star \star\end{array}$ & $\begin{array}{l}.78 \\
\star \star \star\end{array}$ & $\begin{array}{r}.74 \\
\star \star \\
\end{array}$ & 1 \\
\hline Mean & 2.03 & 2.13 & 7.60 & 134 & 2.73 & 4.81 & 2.56 & 10.1 & .54 & .49 & .42 & 1.44 \\
\hline $\begin{array}{l}\text { Std } \\
\text { Dev }\end{array}$ & .93 & .89 & 3.24 & 100 & 2.02 & 3.43 & 2.35 & 6.25 & .91 & 1.00 & .90 & 2.13 \\
\hline
\end{tabular}

${ }^{\star} p \leq .05$

$\star \star p \leq .01$

With Family, and Table II, a correlation matrix for the other dependent variable, Satisfaction With Non-Family, provides that information. In Table I the only variable associated with 
TABLE \|

CORRELATION MATRIX PRESENTING INDEPENDENT VARIABLES AND SATISFACTION WITH NON-FAMILY

\begin{tabular}{|c|c|c|c|c|c|c|c|c|c|c|c|c|}
\hline & $\begin{array}{l}\text { Sat } \\
w / f\end{array}$ & \begin{tabular}{|c|} 
Sat \\
W/nf
\end{tabular} & $\begin{array}{l}\text { Nfam } \\
\text { size }\end{array}$ & $\begin{array}{l}\text { Num } \\
\text { cont }\end{array}$ & $\begin{array}{l}\text { Ad/ } \\
\text { sup }\end{array}$ & $\begin{array}{l}\text { Em/ } \\
\text { sup }\end{array}$ & $\begin{array}{c}\text { Instr } \\
\text { sup }\end{array}$ & $\begin{array}{l}\text { Tot } \\
\text { pos }\end{array}$ & $\begin{array}{l}\mathrm{Ad/} \\
\text { prob }\end{array}$ & $\begin{array}{l}\text { Em/ } \\
\text { prob }\end{array}$ & \begin{tabular}{|c|} 
Instr \\
prob
\end{tabular} & $\begin{array}{l}\text { Tot } \\
\text { neg }\end{array}$ \\
\hline $\begin{array}{l}\text { Sat } \\
w / f\end{array}$ & 1 & & & & & & & & & & & \\
\hline $\begin{array}{l}\text { Sat } \\
w / n f\end{array}$ & $\begin{array}{r}.27 \\
\star \star \\
\end{array}$ & 1 & & & & & & & & & & \\
\hline $\begin{array}{l}\text { Nfam } \\
\text { size }\end{array}$ & .07 & .01 & 1 & & & & & & & & & \\
\hline $\begin{array}{l}\text { Num } \\
\text { cont }\end{array}$ & .04 & .08 & $\begin{array}{l}.45 \\
\star \star \\
\end{array}$ & 1 & & & & & & & & \\
\hline $\begin{array}{l}\mathrm{Ad} / \\
\text { sup }\end{array}$ & .04 & .02 & $\begin{array}{l}.57 \\
\star \star\end{array}$ & .35 & 1 & & & & & & & \\
\hline $\begin{array}{l}\text { Em/ } \\
\text { sup }\end{array}$ & .03 & -.06 & $\begin{array}{l}.66 \\
\star \star\end{array}$ & $\begin{array}{l}.34 \\
\star \star\end{array}$ & $\begin{array}{l}.53 \\
\star \star\end{array}$ & $T$ & & & & & & \\
\hline $\begin{array}{l}\text { Inst/ } \\
\text { sup }\end{array}$ & .06 & .05 & $\begin{array}{l}.49 \\
\star \star\end{array}$ & .36 & $\begin{array}{l}.52 \\
\star \star \star\end{array}$ & $\begin{array}{l}.40 \\
\star \star *\end{array}$ & 1 & & & & & \\
\hline $\begin{array}{l}\text { Tot } \\
\text { pos }\end{array}$ & .05 & -.01 & $\begin{array}{l}.72 \\
\star \star \\
\end{array}$ & $\begin{array}{r}.43 \\
\star \star \\
\end{array}$ & $\begin{array}{r}.83 \\
\star * \\
\end{array}$ & $\begin{array}{r}.85 \\
\star \star \star \\
\end{array}$ & $\begin{array}{r}.74 \\
\star \star \\
\end{array}$ & 1 & & & & \\
\hline $\begin{array}{l}\mathrm{Ad} / \\
\text { prob }\end{array}$ & $\begin{array}{c}-1 \\
\star\end{array}$ & $\begin{array}{r}.20 \\
\star * \\
\end{array}$ & $\begin{array}{l}.28 \\
\star \star \\
\end{array}$ & $\begin{array}{r}.22 \\
\star * \\
\end{array}$ & $\begin{array}{l}.15 \\
\star \star \\
\end{array}$ & $\begin{array}{c}.22 \\
\star * \\
\end{array}$ & $\begin{array}{l}.26 \\
* * \\
\end{array}$ & $\begin{array}{l}.25 \\
\star \star \\
\end{array}$ & 1 & & & \\
\hline $\begin{array}{l}\mathrm{Em} / \\
\text { prob }\end{array}$ & .05 & $\begin{array}{c}-.16 \\
\star \star\end{array}$ & $\begin{array}{l}.15 \\
\star \star \star\end{array}$ & .07 & .00 & .08 & .09 & .07 & $\begin{array}{l}.34 \\
\star *\end{array}$ & 1 & & \\
\hline $\begin{array}{l}\text { Inst/ } \\
\text { prob }\end{array}$ & .01 & -.07 & $\begin{array}{l}.18 \\
\star \star\end{array}$ & $\begin{array}{l}.19 \\
\star * \\
\end{array}$ & $\begin{array}{c}.11 \\
* \\
\end{array}$ & .05 & $\begin{array}{l}.18 \\
\star \star\end{array}$ & $\begin{array}{l}.13 \\
\star \star\end{array}$ & $\begin{array}{c}.24 \\
\star \star\end{array}$ & $\begin{array}{l}.18 \\
\star \star\end{array}$ & 1 & \\
\hline $\begin{array}{l}\text { Tot } \\
\text { neg }\end{array}$ & .04 & $\begin{array}{c}-.21 \\
\star \star \star\end{array}$ & $\begin{array}{l}.29 \\
\star \star\end{array}$ & $\begin{array}{l}.22 \\
\star \star\end{array}$ & $\begin{array}{c}.12 \\
\star\end{array}$ & $\begin{array}{l}.18 \\
\star \star\end{array}$ & $\begin{array}{l}.25 \\
\star \star\end{array}$ & $\begin{array}{l}.22 \\
\star \star\end{array}$ & $\begin{array}{l}.79 \\
\star *\end{array}$ & $\begin{array}{l}.73 \\
\star \star\end{array}$ & $\begin{array}{l}.60 \\
\star \star\end{array}$ & 1 \\
\hline Mean & 2.03 & 2.13 & 6.16 & 95.3 & 2.21 & 3.56 & 1.40 & 7.17 & .30 & .20 & .12 & .63 \\
\hline $\begin{array}{l}\text { Std } \\
\text { Dev }\end{array}$ & .93 & .89 & 3.43 & 80.9 & 2.21 & 3.02 & 1.95 & 5.83 & .66 & .57 & .46 & 1.22 \\
\hline
\end{tabular}

$\star p \leq .05$

$\star * p \leq .01$

Satisfaction With Family is Satisfaction With Non-Family $(r=.27$,

$p, \leq .01)$. In Table II, variables correlated with Satisfaction With 
Non-Family, in addition to Satisfaction With Family, are Advice Problems From Non-Family $(r=-.20, p \leq .01)$, Emotional Problems From Non-Family ( $r=-.16, p \leq .01)$, and the Total Mention Of Problems From Non-Family $(r=-.21, p \leq .01)$. In other words, none of the independent variables measuring family support or problems predict any of the variability on the scale measuring satisfaction with family. In looking at non-family, however, knowing the variables that measure problematic advice and emotional difficulties, as well as the total mentions of problems from non-family members, increases capabilities for predicting the level of satisfaction with people outside the family.

It is interesting to note that for both independent variables, the variables Size Of Network and the Frequency Of Contact are not correlated with satisfaction. That is, it doesn't seem to matter how large a network is and how many times contact is made with network members when trying to predict satisfaction with support. It is also important to note that there are few significant correlations to support the hypotheses stated in the first chapter. Regression analysis looks into this further. Finally, in Table I, Total Negative Mentions are not correlated with Total Positive Mentions although in Table II, for non-family, they are $(r=.22, p \leq .01)$. This means that for family, any positive mentions are not correlated to negative mentions while for non-family the more there are positive mentions the more likely there are to be negative mentions as well.

Table III presents some important information regarding the first hypothesis' prediction that, in general, there will be more 
TABLE III

MEANS AND STANDARD DEVIATIONS OF POSITIVE AND NEGATIVE MENTIONS FOR FAMILY AND NON-FAMILY

\begin{tabular}{|l|c|c|}
\cline { 2 - 3 } \multicolumn{1}{c|}{} & Family & Non-Family \\
\hline Mean Total Positive & 10.10 & 7.17 \\
\hline Standard Deviation Total Positive & 6.29 & 5.83 \\
\hline Mean Total Negative & 1.44 & .63 \\
\hline Standard Deviation Total Negative & 2.13 & 1.22 \\
\hline
\end{tabular}

$n=375$

reported support than reported problems. In both tables, positive mentions exceed negative mentions. For family, Table III shows that the mean of Total Positive Mentions is 10.10 and the standard deviation is 6.29 , while for Total Negative Mentions the mean is 1.44 and the standard deviation is 2.13. For non-family the mean of Total Positive Mentions is 7.17 with a standard deviation of 5.83 and the mean of Total Negative Mentions is .63 with a standard deviation of 1.22 .

\section{RESULTS/REGRESSION ANALYSES}

Regression analyses are used to examine the rest of the hypotheses, including the second part of hypothesis one which predicts that the effects of problems will be greater than the effects of support. In order to read the tables it is important to understand that each column represents a single regression equation. For example, looking at Table IV, the first column depicts a regression equation in which Satisfaction with Family is the dependent variable and Size of Family Network and Frequency of 
TABLE IV

EFFECTS OF NETWORK AND SUPPORT VARIABLES ON SATISFACTION (UNSTANDARDIZED REGRESSION COEFFICIENTS)

\begin{tabular}{|l|c|c|c|c|}
\hline \multicolumn{1}{|c|}{ Independent Variables } & \multicolumn{2}{c|}{$\begin{array}{c}\text { Family } \\
\text { Satisfaction }\end{array}$} & \multicolumn{2}{c|}{$\begin{array}{c}\text { Non-Family } \\
\text { Satisfaction }\end{array}$} \\
\hline Size of Network & .001 & .000 & -.008 & .015 \\
\hline Number of Contacts & .001 & .001 & .001 & $.001^{\star}$ \\
\hline Total Support & & .001 & & -.007 \\
\hline Total Problems & & .002 & & $-.178^{\star \star}$ \\
\hline R Squared & .007 & .007 & .007 & $.062^{\star \star}$ \\
\hline
\end{tabular}

${ }^{*} \mathrm{p} \leq .05$

${ }^{* *} \mathrm{p} \leq .01$

Contact are the independent variables. In the fourth column Satisfaction with Non-Family is the dependent variable and Size of Non-Family Network, Frequency of Contact, Total Mentions of Support, and Total Mentions of Problems are the independent variables. The value for $\mathrm{R}$ Square is always in the last row. Unstandardized regression coefficients are used throughout all the tables because the units of measurement are easy to understand; amount of received support is always measured by the number of people who provide that support and amount of perceived support is always measured on a scale ranging from one to seven.

In Table IV, two regression equations examine satisfaction with support and predict Satisfaction with Family while two regressions predict Satisfaction with Non-Family. For the regressions the Size of the Family Network or Size of the NonFamily Network as well as the Frequency of Contact between the widow and network members are used as background variables, and 
the other independent variables are Total Mentions of Support and Total Mentions of Problems. Initially the background variables are entered into the equation alone. Then positive and negative mentions are simultaneously added to the equation. The results of these four regressions are presented in Table IV.

These regressions support the second part of hypothesis one regarding the relative effects of problems and support. In Table IV, received support does not have a significant effect on satisfaction while received problems in non-family networks do decrease satisfaction. The only significant relationships occur for nonfamily. Total number of problems has a significant effect leading to decreased satisfaction with non-family support. The regression coefficient of $-.178(p \leq .01)$ indicates that for every mention of a person creating problems, satisfaction decreases by .178 on the scale. The partial coefficient for number of contacts is also significant but is quite weak $(r=.001, p \leq .05)$. This coefficient suggests that for an increase in contact with 1 person, Satisfaction With Non-Family increases by .001 , that is, it would take 1000 contacts to increase satisfaction by one point on the scale.

The first two regressions also fail to support the second hypothesis. This hypothesis states that taking into account the negative as well as the positive interactions and using the context of widowhood, there should be a relationship between received and perceived support. Again, received support is measured through respondents' reports of received advice, information and emotional support or problems. Perceived support is measured with a seven 
point scale which rates satisfaction with either family or nonfamily support. Table IV shows that a link between received and perceived support has not been established; all the significance occurs for the non-family negative, not supportive, interactions. Also, the claim that the context of a stressful life event will increase the importance of positive interactions is rejected.

In looking at the third hypothesis, which suggests that family and non-family support should differ, it is clear at this point that there are some differences. While support is not significant for either family or non-family, family problems do not appear significant while non-family problems do. The difference, then, only rests in the arena of problems. There are no differences when examining supportive interactions.

The next set of regression equations examine specifying the type of support and problems in order to predict satisfaction with family and satisfaction with non-family. Size and frequency of contact are consistently the background variables for all equations. To predict satisfaction with support and family, the two background variables are initially the only independent variables in the equation. Then emotional support, instrumental support and helpful advice are regressed individually with only the background variables. These independent variables are ultimately all entered together so that multicolinearity and cumulative effect can be observed. This process is repeated three more times: once with emotional, instrumental and advice problems with family, once with support and non-family, and once with problems and non-family. 
Increasing the specificity of the type of support without exploring the timing of support continues to place all the significant results in the non-family network and in the problem areas. Looking at Table V, Size of Non-Family Network and Frequency of Contact

\section{TABLE V}

EFFECTS OF NETWORK AND TYPE OF PROBLEM ON SATISFACTION WITH NON-FAMILY (UNSTANDARDIZED REGRESSION COEFFICIENTS)

\begin{tabular}{|l|c|c|c|c|c|}
\hline Independent Variables & \multicolumn{5}{|c|}{ Satisfaction With Non-Family } \\
\hline Size of Network & -.008 & -.002 & -.005 & .006 & .008 \\
\hline Num. of Contacts & .001 & .001 & .001 & $.001^{\star}$ & $.001^{\star}$ \\
\hline Emotional Problems & & $-.249^{\star \star}$ & & & -.152 \\
\hline Instrmntl Problems & & & -.162 & & -.057 \\
\hline Advice Problems & & & & $-.315^{\star \star}$ & $.263^{\star \star}$ \\
\hline R Squared & .007 & $.033^{\star}$ & .013 & $.057^{\star \star}$ & $.067^{\star \star}$ \\
\hline
\end{tabular}

${ }^{\star} p \leq .05$

${ }^{\star \star} p \leq .01$

have nonsignificant results, however when Emotional Problems are factored in an effect appears, $(b=-.249, p \leq .01 ; R$ Square $=.033$, $p \leq .05)$. Instrumental Problems have no significant effect at all and Advice Problems have the strongest effect ( $b=-.315, p \leq .01, R$ Square $=.057, p \leq .01$ ). This means that an increase in one negative mention regarding emotional contact decreases satisfaction by $\mathbf{2 4 9}$, or it would take approximately 4 mentions of problems with emotions to decrease satisfaction by one point on the scale. Similarly, it would take approximately 3 mentions of problems with advice to decrease satisfaction with non-family by one point. When all three types of problems are included with Frequency Of Contact 
and Size of Network, they have a small but significant predictive ability ( $R$ Square $=.067, p \leq .01$ ).

The fourth hypothesis suggests that different kinds of support and problems will affect satisfaction with family differently than satisfaction with non-family and these limited effects partially support that hypothesis. Table V, however, presents the only significant results out of the analyses for type of support. Family support and problems are not significant. Even within the nonfamily network there are no significant relationships for support and satisfaction, only for the decrease in satisfaction as a result of problems. This indicates that the different impacts of support and problems are that only problems with advice and emotions affect satisfaction for non-family, and none of the measured variables affect satisfaction for family.

In the next set of analyses, regression analysis is used to examine whether support varies in its effects depending on length of time since widowhood. The background variables of size and frequency of contact are initially alone in the equation, and then positive and negative mentions are added. This is done three times for each cohort and the results are reported in Table VI. Relationships continue to be weak and the significant results occur only for non-family negative interactions. In Cohort One there are no significant results. In Cohort Two, the Total Negative Mentions, controlling for the Size Of Network and Frequency Of Contact, has a regression coefficient of $-.160(p \leq .01)$ which creates an R Square of $.07(p \leq .05)$. All positive mentions continue to be insignificant. The 
TABLE VI

EFFECTS OF NETWORK AND SUPPORT VARIABLES ON NON-FAMILY SATISFACTION BY COHORT (UNSTANDARDIZED REGRESSION COEFFICIENTS)

\begin{tabular}{|l|c|c|c|c|c|c|}
\hline Independent Variables & \multicolumn{2}{|c|}{ Cohort One } & \multicolumn{2}{c|}{ Cohort Two } & \multicolumn{1}{c|}{ Cohort Three } \\
\hline Size of Network & -.008 & -.022 & -.004 & .032 & -.028 & .202 \\
\hline Number of Contacts & .002 & .002 & .001 & .001 & -.001 & -.000 \\
\hline Positive Mentions & & .019 & & -.017 & & .016 \\
\hline Negative Mentions & & -.082 & & $-.160^{\star \star}$ & & $.253^{\star \star}$ \\
\hline R Squared & .107 & .039 & .008 & $.082^{\star}$ & .011 & $.148^{\star \star}$ \\
\hline
\end{tabular}

${ }^{\star} \mathrm{p} \leq .05$

${ }^{\star \star} p \leq .01$

relationships are similar but somewhat stronger in Cohort Three where the regression coefficient for Total Negative Mentions is .253 $(p \leq .01)$ and the R Square for the total equation is .148 ( $p \leq .01)$.

When both type and timing specificity are included in the regression analyses the relationship between perceived support (satisfaction) and received problems appears stronger. Network size and frequency of contact continue to be the background variables, and regression analysis adds variables measuring either support from family, problems from family, support from non-family or problems from non-family. This process is repeated three times, once for each cohort, so that for each cohort four different sets of analyses are conducted. Some of the results from these regressions are presented in Table VII, Table VIII, Table IX and Table X. Interestingly, it is only in the first cohort for non-family that any relationship with support and satisfaction makes a brief appearance. In Table VII instrumental support has a small but significant effect 
TABLE VII

EFFECTS OF NETWORK AND TYPE OF SUPPORT ON SATISFACTION WITH NON-FAMILY BY COHORT (UNSTANDARDIZED REGRESSION COEFFICIENTS)/COHORT ONE

\begin{tabular}{|l|c|c|c|c|c|}
\hline Independent Variables & \multicolumn{5}{|c|}{ Satisfaction With Non-Family } \\
\hline Size of Network & -.007 & .013 & -.026 & -.018 & -.013 \\
\hline Num. of Contacts & .002 & .002 & .001 & .002 & .001 \\
\hline Emotional Support & & .034 & & & -.026 \\
\hline Instrmntl Support & & & $.128^{\star}$ & & $.120^{\star}$ \\
\hline Advice Support & & & & .038 & .016 \\
\hline R Squared & .027 & .033 & $.070^{\star}$ & .032 & .073 \\
\hline
\end{tabular}

${ }^{\star} p \leq .05$

${ }^{\star \star} p \leq .01$

TABLE VIII

EFFECTS OF NETWORK AND TYPE OF SUPPORT ON PROBLEMS WITH NON-FAMILY BY COHORT (UNSTANDARDIZED REGRESSION COEFFICIENTS)/COHORT ONE

\begin{tabular}{|l|r|r|r|r|r|}
\hline Independent Variables & \multicolumn{5}{|c|}{ Satisfaction With Non-Family } \\
\hline Size of Network & -.008 & -.004 & -.010 & -.005 & -.004 \\
\hline Num. of Contacts & .002 & .002 & .002 & .002 & .002 \\
\hline Emotional Problems & & -.186 & & & -.203 \\
\hline Instrmntl Problems & & & .186 & & .227 \\
\hline Advice Problems & & & & -.096 & -.093 \\
\hline R Squared & .027 & .037 & .030 & .031 & .047 \\
\hline
\end{tabular}

${ }^{\star} p \leq .05$
${ }^{\star \star} p \leq .01$ 
TABLE IX

\section{EFFECTS OF NETWORK AND TYPE OF SUPPORT ON PROBLEMS WITH NON-FAMILY BY COHORT (UNSTANDARDIZED REGRESSION COEFFICIENTS)/COHORT TWO}

\begin{tabular}{|l|c|c|c|c|c|}
\hline Independent Variables & \multicolumn{5}{|c|}{ Satisfaction With Non-Family } \\
\hline Size of Network & -.003 & .001 & .008 & .010 & .013 \\
\hline Num. of Contacts & .001 & .001 & .001 & .001 & .001 \\
\hline Emotional Problems & & -.195 & & & .014 \\
\hline Instrmntl Problems & & & -.567 & & -.392 \\
\hline Advice Problems & & & & $-.304^{\star \star}$ & -.214 \\
\hline R Squared & .008 & .025 & $.066^{\star}$ & $.067^{\star}$ & $.088^{\star}$ \\
\hline
\end{tabular}

${ }^{*} p \leq .05$

${ }^{\star \star} \mathrm{p} \leq .01$

TABLE $X$

EFFECTS OF NETWORK AND TYPE OF SUPPORT ON PROBLEMS WITH NON-FAMILY BY COHORT (UNSTANDARDIZED REGRESSION COEFFICIENTS)/COHORT THREE

\begin{tabular}{|l|l|l|l|l|l|}
\hline Independent Variables & \multicolumn{5}{|c|}{ Satisfaction With Non-Family } \\
\hline Size of Network & -.028 & -.015 & -.026 & .013 & .014 \\
\hline Num. of Contacts & -.000 & -.001 & -.000 & -.000 & -.001 \\
\hline Emotional Problems & & $-.370^{\star}$ & & & -.164 \\
\hline InstrmntI Problems & & & -.088 & & .022 \\
\hline Advice Problems & & & & $-.672^{\star \star}$ & $-.602^{\star \star}$ \\
\hline R Squared & .011 & $.087^{\star}$ & .015 & $.201^{\star \star}$ & $.213^{\star \star}$ \\
\hline
\end{tabular}

${ }^{*} \mathrm{p} \leq .05$

${ }^{* \star} p \leq .01$

on satisfaction. The regression coefficient is .128 ( $p \leq .05)$ and provides an R Square of .070 ( $p \leq .05)$ in an equation where network size and frequency of contact are insignificant. When all three types of support are added into the regression, instrumental support continues to be the only independent variable which is significant. 
In Cohort Two and Cohort Three, support does not affect satisfaction.

Cohort One also stands out in the analysis of how different types of problems affect non-family satisfaction, as it is the only time when none of the three types of problems have any effects, as shown in Table VIII. Table IX provides information on problems and satisfaction for the second cohort. Advice Problems decrease Satisfaction with Non-Family $(b=-.304, p \leq .01)$ and so do Instrumental Problems $(b=-.567, p \leq .01)$. When all three negative mentions are analyzed at the same time, the significance of the separate coefficients disappear due to multicolinearity and the $R$ Square approaches significance at .09 ( $p \leq .05)$, an increase from the previous levels of .067 and .066 ( $p \leq .05)$.

Table $X$ shows that in the third cohort the significance of negative interactions becomes even stronger. Instrumental Problems have no effect while Problems with Emotions, when controlling for Frequency Of Contact and Size Of Network, are able to predict almost $9 \%$ of the variation in Satisfaction With NonFamily Support(R Sq. $=.087, \mathrm{p} \leq .05)$. Advice Problems are able to predict $20 \%$ of the variation $(p \leq .01)$. The regression coefficient for Emotional Problems is $-.37(p \leq .01)$ and the regression coefficient for Advice Problems is -.67 ( $p \leq .01$ ). When all three types of problems are added into the equation along with Frequency of Contact and Size Of Network, the R Squared is .21 $(p=.01)$. The significance of emotional effects disappears as a result of multicolinearity. 
It is interesting that in Cohort Two Advice Problems and Instrumental Problems are important determinants of satisfaction while in Cohort Three Advice Problems and Emotional Problems are important. This suggests that it may be advice around instrumental issues that is an issue to widows in Cohort Two while advice around emotional issues is problematic for Cohort Three. The high level of multicolinearity in both equations supports this supposition, indicating that advice is closely connected with the other constructs.

It is also important to note that the strength of the problematic relationships seems to increase as the widow gets further from the event of widowhood. In Cohort One problematic interactions were not significant, in Cohort Two the negative interactions predicted $8 \%$ of the variability of Satisfaction With Non-Family, and in Cohort Three problems with advice and emotions predicted $21 \%$ of the variability of Satisfaction With Non-Family.

These data provide partial support for hypothesis number five which predicts that the effects of support and problems on satisfaction will vary over time. Again, there are no significant relationships for family satisfaction, support and problems. Interestingly, however, it does appear that problems with support in non-family networks change and grow over time. Also, while there is only one instance of a significant relationship between received support and Satisfaction With Non-Family Support, it would have been overlooked without increasing specificity of timing and type of support. 


\section{SUMMARY OF FINDINGS}

In summary, these analyses indicate that most relationships between perceived and received support are not significant. It is possible, however, to miss even the significant results if source, type, and timing specificity are not taken into account. There are no significant relationships for Satisfaction With Family despite increasing levels of specificity, but there are significant relationships for Satisfaction with Non-Family which are the strongest when type and timing of support are specified. Effects are significant when considering advice and instrumental problems in the second cohort and advice and emotional problems in the third cohort. Also, instrumental support has a slight effect on increasing satisfaction with non-family networks in the first cohort. 


\section{CHAPTER IV}

\section{CONCLUSION}

Although it makes intuitive sense to suppose that the actual amounts of support received will affect a person's satisfaction with support, most studies have been unable to find that link between perceived support and received support. Some authors believe that in order for this link to be established specificity needs to be defined: that it would be easier to establish a link between received and perceived support if the context of the event, the positive and negative aspects of interactions, source specificity, type specificity and timing specificity are taken into account. This analysis considered all those issues in order to establish a link between perceived and received support. While some of the hypotheses are partially supported, many of the predicted results did not occur.

Clearly it is important, as the first hypothesis suggests, to separate the positive from the negative. Certainly both social support and what Rook (1990) calls social strain are different constructs. However the results of this study only show effects for non-family relationships and are able to explain best the effect of negative interactions on satisfaction with support. The first hypothesis predicts that there will be more reported support than 
problems, although problems will have a greater effect. In this study problems were reported less, and problems with non-family did have a significant effect. The effects of reported non-family support are almost zero, with the exception of instrumental support in the first cohort.

The second hypothesis, that there should be a predictive relationship between the support that is received and perceptions of support, is unsupported. The context of a stressful life event makes no clear difference in strengthening the link between received and perceived support, as suggested by Dunkel-Schetter and Bennett (1990) and Morgan and March (1992). And while it is valuable to differentiate between negative and positive interactions, the relationship between received and perceived support never materialized.

Adding specificity makes a difference when examining problems and non-family, but there is only a slight relationship between received instrumental support from non-family and satisfaction. Disappointingly, nothing seemed to establish a link between received support from family members and perceived support, even when support is specified by type and timing. This suggests that the third hypothesis, which states there is a difference between family and non-family support, is not entirely off target; the effects of problems and instrumental support on nonfamily are significant while there are no significant relationships for family at all. 
The data provide some support for the fourth and fifth hypotheses. The general prediction of the fourth hypothesis, that types of support and of problems will affect satisfaction differently for family and non-family, is supported in that only problems with non-family have any impact on satisfaction. The fifth hypothesis, which suggests that satisfaction will also vary over time, is also only partially supported. Not only is there no significance related to family support or problems, the only time that non-family support affects satisfaction is in the first cohort. Clearly, however, there are some differences in satisfaction based on the types and timing of problems.

The most important and surprising findings in this analysis are that all the links between support, problems and satisfaction are in the non-family network, and that problems with non-family increase in strength as time passes. This leads to three obvious questions: Why is all the effect on satisfaction in the non-family network? Why do the effects of problems increase? Why are the effects of problems so prevalent? Rook (1987) suggests that negative interactions are more important to individuals for three reasons: rare negative exchanges are salient, these behaviors appear to reflect bad intent on the part of the network member, and humans may have an innate tendency to pay more attentions to threats than to pleasure. These explanations are somewhat vague for the purposes of this study, however. It is possible that in or after a crisis, when support is expected as a rule, negative experiences do have a powerful effect. 
The literature provides little in the way of clues as to why the importance of negative interactions increase over time. It is possible to turn to the discussion of role transitions by Walker, MacBride, and Vachon (1977) for some ideas. They suggest that in the later stages of widowhood a widow may need the kinds of ties that will help her make a transition into her new role. In the context of transition, it is possible to imagine that problematic advice could be seen as particularly stifling and upsetting. It is also possible that women experiencing the loss of a spouse are likely to be thankful for all kinds of help early in the grieving process. It may only be later that they have the ability and inclination to evaluate those interactions, assessing whether or not they are truly supportive. Interestingly, Rook and Pietromonoco (1987) write that one way relationships change over time is that negative exchanges become more common.

It is also important to ask why all the action is in the nonfamily network. The data indicate that satisfaction from family has little to do with received support and problems. Maybe this is because widows are used to positive as well as negative experiences within their families, and their basic levels of satisfaction have little to do with the particulars of recent interactions. Perhaps, within families, satisfaction is more related to the history of such interactions. It is also possible that there is a sense that there is little one can do to change family. Friends, however, one can pick and choose, so it makes sense to mull over the qualities of those relationships. 
It is also possible to imagine that women might be reluctant to discuss problems with family members. A sense of privacy when it comes to family matters is not uncommon. Many people are not willing to "air their dirty laundry" in public. Also, women might feel that discussing problems with their children might make them seem to be inadequate parents. Both these reasons could lead to an underreporting of family problems. It could be that as the study continues and women become more comfortable with the interviews and the interviewers, stronger information about problems with family members will surface.

Still, it is disappointing that this study is unable to establish a link between received and perceived support in the family network. It may be, as Sarason, Sarason and Pierce (1990b) suggest, that perceived support is primarily a function of personality. It may also be, as Dunkel-Schetter and Bennett (1990) theorize, that expectations of support and the victimization process mediate the relationship between perceived and received support. It is also possible that the link between perceived and received support exists but that the measures in this particular study are unable to capture it. Possibly received support should be operationalized in some other fashion, or close ended survey techniques are unable to uncover the meaning of support and how people feel about it. Finally, it may be that there simply is no relationship between what people get in terms of social support and how satisfied they are with it. The question continues to deserve further exploration. 


\section{SELECTED BIBLIOGRAPHY}

Antonucci, T. .(1990.) Social Support and Social Relationships. In Robert H. Binstock and Linda K. George (Eds), Handbook of Aging and the Social Sciences (3rd ed.). New York: Academic Press.

Arling, G. (1976.) The Elderly Widow and her Family, Neighbors and Friends. Journal of Marriage and the Family. 38: 757-768

Bankoff, E. (1983.) Social Support and Adaptation to Widowhood. Journal of Marriage and the Family. 45: 827-839.

Bankoff, E. (1984.) The Long-Term Consequences of Social Support for Newly Widowed Women. Paper presented at the Sunbelt Social Network Conference. Phoenix, Arizona.

Bengston, V., Rosenthal, C., \& Burten, L. 1990. In Robert H. Binstock and Linda K. George (Eds), Handbook of Aging and the Social Sciences (3rd ed.). New York: Academic Press.

Dunkel-Schetter, C., \& Bennett, T. (1990.) In Barbara Sarason, Irwin Sarason and Gregory Pierce (eds.) Social Support: An Interaction View. New York: John Wiley and Sons.

Ferraro, K. (1984.) Widowhood and Social Participation in Later Life. Research on Aging. 6: 451-468.

Ferraro, K. (1989.) Widowhood and Health. In Kyriakos S. Markides and Cary L. Cooper (Eds.) Aging, Stress and Health. New York: John Wiley and Sons Ltd.

George, L. (1990.) Social Structure, Social Processes and SocialPsychological Stress. In Robert H. Binstock and Linda K. George (Eds), Handbook of Aging and the Social Sciences (3rd ed.). New York: Academic Press.

Gore, S. (1989.) Social Networks and Social Support in Health Care. In Howard E. Freeman and Sol Levine (Eds.) Handbook of Medical Sociology (4th ed.). New Jersey: Prentice Hall. 
Hirsch, B. (1980.) Natural Support Systems and Coping with Major Life Changes. American Journal of Community Psychology 18: 159-172.

Hobfall, S., \& Parris Stephens, M. (1990.) Social Support During Extreme Stress: Consequences and Intervention. In Barbara Sarason, Irwin Sarason and Gregory Pierce (eds.) Social Support: An Interaction View. New York: John Wiley and Sons.

House, J., Umberson, D., \& Landis, K. (1988.) Structure and Processes of Social Support. American Review of Sociology. 14: 293-318.

Jackson, P. (1992.) Specifying the Buffering Hypothesis: Support, Strain and Depression. Social Psychology Quarterly. 4: 363378.

Jacobson, D. (1986.) Types and Timing of Support. Journal of Health and Social Behavior. 27: 250-264.

Krause, N. (1989.) Issues of Measurement and Analysis in Studies of Social Support, Aging and Health. In Kyriakos S. Markides and Cary L. Cooper (Eds.) Aging, Stress and Health. New York: John Wiley and Sons Ltd.

Morgan, D. (1989.) Adjusting to Widowhood: Do Social Networks Really Make it Easier? The Gerontologist. 29: 101-107.

Morgan, D. (1990.) Combining the Strengths of Social Networks, Social Support, and Personal Relationships. In Steve Duck and Roxanne Cohen Silver (Eds.) Personal Relationships and Social Support. Newbury Park, California: Sage.

Morgan, D., \& March, S. (1992.) The Impact of Life Events on Networks of Personal Relationships: A Comparison of Widowhood and Caring for a Spouse with Alzhiemer's Disease. Journal of Social and Personal Relationships. 9: 563-584.

Norris, F., \& Murrell, S. (1990.) Social Support, Life Events and Stress as Modifiers of Adjustment to Bereavement by Older Adults. Psychology and Aging. 5: 429-436. 
O'Brien, R. (1987.) Role of Social Support in Bereavement Outcomes. Paper presented at the 40th Annual Scientific Meeting of The Gerontological Society of America. Washington, D.C.

O’Bryant, S., \& Morgan, L. 1990. Recent Widows' Kin Support and Orientations to Self-Sufficiency. The Gerontologist. 30. 391398.

Rook, K. (1990.) Parallels in the Study of Social Support and Social Strain. Journal of Social and Clinical Psychology. 9: 118-132.

Rook, K. 1990. Stressful Aspects of Older Adults' Social Relationships: Current Theory and Research. In Mary Ann Parris Stephens, Janis H. Crowther, Steven E. Hobfall and Daniel L. Tennenbaum (Eds.) Stress and Coping in Later-Life Families. Hemisphere Publishing Corporation: New York.

Rook, K., \& Pietromonoco, P. (1987.) Close Relationships: Ties that Heal or Ties that Bind. Advances in Personal Relationships. 1: 1-35.

Sarason, B., Sarason, I., \& Pierce, G. (1990.) Traditional Views of Social Support and Their Impact on Assessment. In Barbara Sarason, Irwin Sarason and Gregory Pierce (eds.) Social Support: An Interaction View. New York: John Wiley and Sons.

Sarason, B., Sarason, I., \& Pierce, G. (1990.) Social Support: The Sense of Acceptance and the Role of Relationships. In Barbara Sarason, Irwin Sarason and Gregory Pierce (eds.) Social Support: An Interaction View. New York: John Wiley and Sons.

Schwarzer, R., \& Leppin, A. (1991.) Social Support and Health: A Theoretical and Empirical Overview. Journal of Social and Personal Relationships. 8: 99-127.

Stroebe, M., \& Stroebe, W. (1985.) Social Support and the Alleviation of Loss. In Barbara Sarason and Irwin Sarason (eds.) Social Support: Theory, Research and Applications. Boston: Martinus Nijhoff Publishers.

Talbott, M. (1990.) The Negative Side of the Relationship Between Older Widows and Their Adult Children. The Gerontologist. 30: 595-603. 
Vachon, M., \& Stylianos, S. (1988.) The Role of Social Support in Bereavement. Journal of Social Issues. 44: 175-190.

Walker, K., MacBride, A., \& Vachon, M. (1977.) Social Support Networks and the Crisis of Bereavement. Social Science and Medicine. 11: 34-41. 